\title{
Closure in Surface Flux Estimation by Energy Balance Model: Comparison of Priestly-Taylor and Penman-Monteith Computations for a Tropical Site in Ibadan
}

\author{
Josiah O. Aramide ${ }^{*} \quad$ Mojisola O. Adeniyi ${ }^{2}$ \\ 1.Department of Physics, Adeyemi College of Education, PMB 520, Ondo 351101, Nigeria \\ 2.Department of Physics, University of Ibadan, Ibadan 200213, Nigeria
}

\begin{abstract}
Increasing demand to further understand complexity in surface energy flux partitioning necessitates the adaptation of numerous estimation methods to fit the site of observation. This is useful for reducing the uncertainty in physically measurable parameters especially those in tropical regions with high human interference in the atmospheric boundary layer. In this study, we used computations from two methods - the Priestley-Taylor (PT) and the Penman-Monteith (PM), based on the Energy Balance model to ascertain closure performance in the surface flux estimations. The study was carried out at the Nigerian Meteorological Experiment III site $\left(7.38^{\circ} \mathrm{N}\right.$ and $\left.3.93^{\circ} \mathrm{E}, 224.2 \mathrm{~m}\right)$ located in Ibadan, Southwest Nigeria. Thirty days of a year (2006) dataset were examined using the Bowen ratio (BR) energy balance model to validate the PT and PM methods. The systems were examined across daily and diurnal cycles to better understand the differences in energy partitioning. Results showed that both systems generally favored latent heat flux compared to sensible heat flux perhaps due to above-normal rainfall during the period. The PM method performed better than the PT method with a period average for the sensible heat and latent heat fluxes as $32.05 \mathrm{Wm}^{-2}$ and $67.66 \mathrm{Wm}^{-2}$ respectively, accounting for $29.22 \%$ and $61.39 \%$ of the total net radiation. The PT method underestimates the sensible heat flux by as much as $19.70 \mathrm{Wm}^{-2}$ compared to the PM method, with a period average of $12.36 \mathrm{Wm}^{-2}$ representing $11.26 \%$ of total net radiation. The PM method also gives a period average Bowen ratio estimate of 0.55 , consistent with the standard range for grasslands. The study suggests that the performance of the PM method is related to its response to heat and water vapor transfer over humid regions and would contribute to further research on land-surface interactions over the tropics. Finally, we propose that the measurement of available energy, net radiation, and ground heat flux should be separated for different collocated systems in order to reduce the forcing of closure and aid in proper partitioning of the fluxes.
\end{abstract}

Keywords: surface energy flux, energy balance model, Priestly-Taylor, Penman-Monteith, West Africa, latent heat, sensible heat, NIMEX_3

DOI: $10.7176 / \mathrm{JEES} / 11-5-0 \overline{5}$

Publication date:May $31^{\text {st }} 2021$

\section{Introduction}

Although the sun is the source of all the energy that drives the atmospheric machinery, it is important to be reminded that the earth's surface plays a convincing role in converting the solar radiation into sensible heat. The processes of converting the constant energy (radiation) from the sun to other forms constitute the energy budget of the earth's surface and its atmosphere. In order to maintain a balanced budget of heat, the earth-atmosphere system has to operate in specific manner. For instance, heat and moisture are in continuous exchange between the earth and the atmosphere. These convective exchanges constitute the surface fluxes in the atmosphere, with the convective exchange of heat as sensible heat flux, $\mathrm{H}$ and the convective exchange of moisture as latent heat flux, LE.

\subsection{The closure problem}

At any particular instance, the atmospheric heat gain is rarely equal to the loss, and this accounts for much of the variability of the weather sequences. As shortwave radiation comes into our planet, a part of it is intercepted and reflected back to space by the clouds. The net radiation (Rn) at the earth's surface (assuming no snow cover) is either absorbed into the ground in the form of ground heat flux $(\mathrm{G})$ or transferred to the atmosphere in the form of $\mathrm{H}$ and LE.

Closure (i.e., $\mathrm{Rn}-\mathrm{H}$ - LE - $\mathrm{G}=0$ ) is one tool used to quantify the reliability and accuracy with which these components of the surface energy fluxes are estimated. Unfortunately, most field measurements and experimental data, alone, have failed to show closure of the surface energy budget. Instrument error, changes in surface heterogeneity and fetch can all affect these measurements with large observed discrepancies between available energy and the sum of the turbulent fluxes of H and LE (Foken et al., 2011; Fritschen and Simpson, 1989a; Stannard, 1993; Twine et al., 2000). Improvements in modelling have also not answered all questions for the fundamental processes in the atmosphere. Notably, mesoscale and storm-scale models do not completely 
account for horizontal variations in surface fluxes that play a pivotal role in the location of atmospheric phenomena.

\subsection{Some approaches to flux estimation}

According to (Brotzge and Crawford, 2003), it is necessary to develop a reliable method of monitoring closure in the surface energy budget. This contributes to the development and validation of numerical models. Even though closure remains difficult to achieve with measuring systems, there have been great strides made in the ability to evaluate the surface fluxes with closure of the energy balance model using different methods (Foken et al., 2011; Mauder et al., 2020). Attempts using the eddy-covariance method (Barr et al., 2006; Castellví et al., 2008; Twine et al., 2000) have approached the closure problem with an understanding that systematic flux parameterizations can be useful in proposing empirical closure functions for models. Likewise, research into the independent estimation of the fluxes using either a single source energy balance model (Fritschen and Simpson, 1989b; Yang et al., 2004) or modified standard methods like the Bowen ratio (Liu and Foken, 2001), avoid closure problems from the surface energy balance model. Other authors (Akinnubi and Adeniyi, 2019; Collaizi, Paul D. et al., 2014; Heusinkveld et al., 2004; Mauder et al., 2020; Stannard, 1993; Suleiman and Hoogenboom, 2007) have compared the performance of different methods in estimation of surface fluxes for specific regions and applications. In one instance, (Collaizi, Paul D. et al., 2014) shows that since surface temperatures are usually available at only a single view angle, additional equations are required to compute the soil and canopy temperatures, which govern sensible heat flux exchange.

To properly predict weather systems, adequate partitioning of the available energy, into the surface fluxes, needs to be achieved. It is clear from the literature that reasonable closure of the surface energy budget remains a difficult and elusive problem. One way to identify systematic problems associated with closure is to evaluate the performance of collocated, independent measurement systems in adequately parameterizing and partitioning the available energy into the surface fluxes. Then, compare the performance of a reliable method of equations for computing and monitoring the surface energy budget with these results. Although different researchers have studied the surface energy budget using several methods, only few were able to use the Priestley-Taylor and the Penman-Monteith methods especially within the tropics. These previous efforts have been limited to data collected during relatively short periods whereas long-term datasets (in order of months) as well as extended periods of comparison are needed to adequately address issues of closure from instrument, seasonal bias and trends associated with a measurement site. In this work, we compare improved versions of diagnostic methods that are able to calculate surface energy fluxes independently using NIMEX_3 data. Thirty days of a year dataset collected to evaluate the Priestley-Taylor (PT), Penman-Monteith (PM) against the standard Bowen ratio (BR) energy balance model. The methods are analyzed to obtain the surface flux partitions of the available energy. Inquiry is also made into the differences between the systems across diurnal and daily cycles to better understand non-closure of the energy budget. The extent of partitioning and the differences between the two methods is also examined to determine a relationship and to explain the observed patterns in closure.

\section{Materials and Method}

\subsection{The Study Area}

The data used in this investigation was collected from the Nigeria Micrometeorological Experiment (NIMEX 3) site situated in University of Ibadan at a location of $7.38^{\circ} \mathrm{N}$ and $3.93^{\circ} \mathrm{E}$, towards the South of the University. The elevation of the site above the sea level is $224.2 \mathrm{~m}$. The site is on extensive flat non-vegetated land (bare soil) that provides a general overview of energy fluxes, wind speed and the cloud situations. This station records incoming solar radiation, air temperature, relative humidity, wind speed and direction, soil temperature, soil heat flux, barometric pressure, and rainfall at determinable intervals.

The fundamental Bowen Ratio/Energy Balance method is chosen for the site since it is considerably homogeneous with bare-soil cover reducing the demand for high measurement resolution and accuracy (resulting from small temperature and humidity gradients), as is the case in sites with canopy or vegetative cover, where a high degree of turbulent mixing occurs.

\subsection{Data Collection}

Thirty-day data set of a year was collected from the NIMEX 3 site, falling within Julian days 83 to 123 and sufficiently characterized by sunny, as well as rainy days. The station measures up to 14 meteorological parameters such as air temperatures at $3 \mathrm{~m}, 6 \mathrm{~m}$ and $12 \mathrm{~m}$, soil temperature, wind speed etc., over an observation period of 10 minutes. It also measures soil temperatures at different sub-levels of the soil strata, but that data was not used for this work. Measurements complexes were sampled every second and the averaged values stored at 1 min intervals. The eddy covariance system used was sampled at the speeds of $16 \mathrm{~Hz}$ and $8 \mathrm{~Hz}$ respectively. 
Table 1. List of equipment/sensors used for the NIMEX 3 field measurements

\begin{tabular}{|l|l|l|l|}
\hline SENSORS & MODEL & \multicolumn{1}{|c|}{ ACCURACY } & HEIGHT/DEPTHS \\
\hline Datalogger & $\begin{array}{l}\text { Campbell Scientific } \\
\text { CR23X }\end{array}$ & Not applicable & $1 \mathrm{~m}$ \\
\hline Anemometer & R.M. Young & Dist. Const. $2.3 \mathrm{~m}$ & $3 \mathrm{~m}, 6 \mathrm{~m}$ and $12 \mathrm{~m}$ \\
\hline Frankenberger Psychometer & Theodor Friedrichs & $0.05^{\circ} \mathrm{C}$ & $6 \mathrm{~m}$ and $12 \mathrm{~m}$ \\
\hline Wind vane & Vector instruments & Dist. Const. $2.3 \mathrm{~m}$ & $14.5 \mathrm{~m}$ \\
\hline Soil heat flux plate & Hukseflux Middleton & $50 \mathrm{mV} / \mathrm{Wm}^{-2}$ & $2 \mathrm{~cm}$ \\
\hline Soil moisture probe & Campbell scientific & $\pm 3 \%$ of water content & $0-5 \mathrm{~cm}$ deep to the soil \\
\hline Net radiometer & Kipp and Zonen & $+9.6 / 11.9 \mathrm{mV} / \mathrm{Wm}^{-2}$ & $1 \mathrm{~m}$ \\
\hline Pyranometer & Kipp and zonen & $+13.6 \mathrm{mV} / \mathrm{Wm} \mathrm{m}^{-2}$ & $1 \mathrm{~m}$ \\
\hline Rain gauge ARG100 & Campbell scientific & $0.203 \mathrm{~mm} / \mathrm{TIP}$ & $2 \mathrm{~m}$ \\
\hline Capacitive barometer & Ammoinit & $1 \mathrm{hpa}$ & $3 \mathrm{~m}$ \\
\hline $\begin{array}{l}\text { Ultrasonic anemometer UAS- } \\
1\end{array}$ & Mekek & $10 \mathrm{~Hz}$ & $6 \mathrm{~m}$ \\
\hline Krypton hygrometer & Campbell scientific & $10 \mathrm{~Hz}$ & $6 \mathrm{~m}$ \\
\hline
\end{tabular}

\subsection{Data Analysis}

The data collected was carefully analyzed using spreadsheet software available on most microcomputers according to the two chosen parameterization models: Priestley-Taylor, and Penman-Monteith.

2.3.1 The Priestley-Taylor Method (PT)

As described by Priestley and Taylor (1972), this system involves a higher level of sophistication which comes by recognizing that to first order, we can use K-theory to approximate the fluxes by gradients of temperature and humidity in the Bowen ratio, assuming that $\mathrm{K}_{\mathrm{E}}=\mathrm{K}_{\mathrm{H}}$ :

$$
\beta=\gamma \frac{\partial \bar{\theta} / \partial z}{\partial \bar{q} / \partial z}=\frac{\left[\gamma\left(\partial \bar{T} / \partial z+\Gamma_{\mathrm{d}}\right)\right]}{\partial \bar{q} / \partial z}
$$

where $\Gamma_{\mathrm{d}}$ is the dry adiabatic lapse rate of $9.8 \mathrm{~K} / \mathrm{km}$. If the air is saturated (i.e., if $\mathrm{q}=\mathrm{q}_{\mathrm{sat}}$ ), then the change of specific humidity with temperature is given by the Clausius-Clapeyron equation.

$$
\frac{d q_{s a t}}{d T}=\frac{\varepsilon L_{v} \bar{q}_{s a t}}{\left(\Re \bar{T}^{2}\right)} \equiv S_{c c}(\bar{T})
$$

where $\varepsilon=0.6244\left(\mathrm{~g}_{\text {water }} / \mathrm{g}_{\text {air }}\right)$ is the ratio of gas constants for air and water vapor.

We can use a variation of Teten's formula to find qsat as a function of temperature:

where.

$$
q_{\text {sat }}=0.6244 \frac{e_{\text {sat }}}{P}
$$

$$
e_{\text {sat }}=(0.6112 k P a) * \exp \left[\frac{17.67(T-273.16)}{T-29.66}\right]
$$

for $\mathrm{T}$ in degrees Kelvin.

If we replace $\overline{\partial \bar{q} / \partial z}$ by $\overline{s_{c c}(\bar{T}) * \partial \bar{T} / \partial z}$, then:

$$
\beta=\frac{\left[\gamma\left(\partial \bar{T} / \partial z+\Gamma_{\mathrm{d}}\right)\right]}{\left(s_{c c} \partial \bar{T} / \partial z\right)}
$$

or

$$
\beta=\frac{\gamma}{s_{c c}}+\frac{\gamma \cdot \Gamma_{\mathrm{d}}}{s_{c c}(\partial \bar{T} / \partial z)}
$$

If one neglects the last term in (1.1f), then substitute back into expressions for $\mathrm{H}$ and LE, yields the PriestleyTaylor parameterization:

$$
\begin{gathered}
H_{P T}=\frac{\left[\left(1-\alpha_{P T}\right) s_{c c}+\gamma\right]\left(R_{n}-G\right)}{\left(s_{c c}+\gamma\right)} \\
L E_{P T}=\alpha_{P T} s_{c c} \frac{\left(R_{n}-G\right)}{\left(s_{c c}+\gamma\right)}
\end{gathered}
$$


where the parameter $\overline{\alpha_{P T}}$ is introduced to make up for neglecting the last term as described, and to allow the equations to be used for unsaturated conditions (Fritschen and Simpson, 1989b).

In more complex turbulent systems, the Priestley-Taylor method can yield incorrect fluxes when advection is happening. Although one possible fix is to increase the magnitude of $\overline{\alpha_{P T}}$, many investigators (Field et al., 1992; Kilinc et al., 2012; Leuning et al., 2012; Massman, 1993) prefer to add an additional advection term, A, to the moisture flux equation to yield:

$$
L E_{P T}=s_{C C} \frac{\left(R_{n}-G\right)}{\left(s_{C C}+\gamma\right)}+A
$$

This same advection term must be subtracted from the equation for heat flux.

2.3.2 The Penman-Monteith Method (PM)

The Penman-Monteith parameterization provides for the inclusion of the evaporative cooling effects such as occur during advection via a correction term, $\mathrm{F}_{\mathrm{w}}$, added to the Priestley-Taylor forms (Adeniyi and Otunla, 2010; Collaizi, Paul D. et al., 2014; Stannard, 1993; Suleiman and Hoogenboom, 2007). The parameterization is of the form:

$$
\begin{aligned}
& H_{P M}=\frac{\left[\gamma\left(R_{n}-G\right)-F_{w}\right.}{\left(X_{G} s_{c c}+\gamma\right)} \\
& L E_{P M}=\frac{\left[X_{G} s_{c c}\left(R_{n}-G\right)+F_{w}\right.}{\left(X_{G} s_{c c}+\gamma\right)}
\end{aligned}
$$

where $\bar{X}_{G}$ is like a relative humidity of the earth or plant surface. $\mathrm{F}_{\mathrm{w}}$ is like a specific humidity flux, and is approximated by a bulk transfer law of the form:

$$
F_{w}=C_{E} \bar{M}\left(X_{G}-X_{S}\right) \cdot \bar{q}_{s a t}
$$

where $\bar{X}_{S}$ is the relative humidity of the air near the surface

Remembering that $\overline{C_{E} \bar{M}}$ is like a conductance for moisture, we see that surfaces with greater water conductivity have a greater latent heat flux and smaller sensible heat flux than less conductive surfaces.

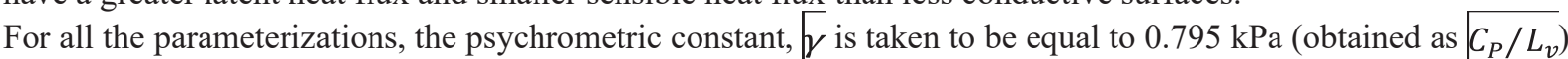
for pressure $=9855 \mathrm{hPa}$ (approx. $100 \mathrm{kPa}$ ) and $\mathrm{T}=20^{\circ} \mathrm{C}$ for the site. For the first method, three different ratios for the temperature measurement height (gradient) were used:

$$
\frac{\Delta T}{\Delta z}: \quad T_{1}=\frac{T_{d 2}-T_{d 1}}{z_{2}-z_{1}}, T_{2}=\frac{T_{d 3}-T_{d 2}}{z_{3}-z_{2}}, T_{3}=\frac{T_{d 3}-T_{d 1}}{z_{3}-z_{1}}
$$

where, $\mathrm{T}_{\mathrm{d} 1}=$ dry bulb temp. @ $\mathrm{z}_{1}=3 \mathrm{~m}, \mathrm{~T}_{\mathrm{d} 2}=$ dry bulb temp. @ $\mathrm{z}_{2}=6 \mathrm{~m}$, and $\mathrm{T}_{\mathrm{d} 3}=$ dry bulb temp. @ $\mathrm{z}_{3}=12 \mathrm{~m}$. The vapor pressure gradient is also obtained in similar fashion but first, we determine the vapor pressure from the Penman Penman equation: equation (since vapor. pressure, $e$ varies with temp, T).

$$
e_{a}=0.6108 \exp \left[\frac{17.27 T}{T+237.3}\right]
$$

and then using an expression similar to that of the temperature gradient above (3.11) we determine the ratios for vapor pressure gradients $\overline{e_{1}, e_{2}}$ and $\overline{e_{3}}$.

The second method uses $\overline{\alpha_{P T}=1.25}$ (since the surface is bare-soil with acceptable wetness) with no additional advection term. The third method assumes that $\overline{C_{E}=0.002}, \overline{X_{S}=0.5}, \overline{X_{G}=0.9}$, and $\overline{\bar{M}}=1.56 \mathrm{~m} / \mathrm{s}$ (obtained from the wind speed data). In the second and third methods, the latent heat of vaporization is approximated by a linear function of temperature:

in $\mathrm{J} / \mathrm{kg}$. The specific heat at constant pressure is assumed to be constant $C_{P}=1005 \mathrm{~J} /(\mathrm{KgK})$, and the gas constant for air is also assumed to be constant $\Re=287.04 \mathrm{~J} /(\mathrm{kgK})$. Both methods are a function of $\overline{S_{c c}}$ which in turn is a function of temperature. We also compute the Bowen ratio for these two methods upon obtaining the surface fluxes.

The topic of fluxes across vegetation systems is a complex one and we can only barely parameterize as 
shown with the above methods. A more detailed analysis could include factors such as canopy height, vegetation coverage, displacement heights, roughness lengths, plant reflectivity, plant architecture, root zone depth, ground water depth, heat conductivity, soil moisture, and stomatal resistance (Barr et al., 2006; Field et al., 1992; Ha and Mahrt, 2003; Kilinc et al., 2012).

\subsubsection{Surface Energy Balance Closure}

(Beljaars and Holtslag, 1991; Castellví et al., 2008) affirmed that the closure of surface energy budget is an accepted factor in the assessment of the quality of collocated independent measurement systems. The reliability of the methods is assessed using Energy Budget Closure (EBC) given as;

$$
E B C=\left(\frac{H+L E}{R_{n}-G}\right) * 100
$$

where available energy, $E_{A}=R_{n}-G$.

The closure of the surface energy budget for the Nimex 3 site can be obtained from the regression plot of $H+L E$ and $\overline{R_{n}-G}$. The ratio of the sum of $\overline{H+L E}$ and $\overline{R_{n}-G}$ for the period under consideration is considered as an alternative method to evaluate closure.

Table 2. Heat Fluxes estimated by both methods and their Bowen Ratio equivalents on Day 97

\begin{tabular}{|c|c|c|c|c|c|c|c|c|c|c|c|c|}
\hline LST-hr & $G$ & $R n$ & $R n-G$ & $L E(B R)$ & $H(B R)$ & $\beta(B R)$ & $L E(P T)$ & $H(P T)$ & $\beta(P T)$ & $L E(P M)$ & $H(P M)$ & $\boldsymbol{\beta}(\boldsymbol{P M})$ \\
\hline 01:00 & -22.3667 & -15.7983 & 6.5683 & 4.6410 & 1.9273 & 0.4153 & 4.9321 & 1.6362 & 0.3317 & 3.7915 & 2.7768 & 0.7324 \\
\hline 02:00 & -18.5167 & -9.9928 & 8.5238 & 5.9961 & 2.5277 & 4216 & 6.3607 & 2.1631 & 0.3401 & 4.8838 & 3.6401 & 0.7453 \\
\hline 03:00 & -17.4583 & -8.6345 & 8.8238 & 6.1886 & 2.6352 & 4258 & 6.5588 & 2.2650 & 0.3453 & 5.0341 & 3.7897 & 0.7528 \\
\hline 04:00 & -14.8117 & -3.3082 & 11.5035 & 8.0859 & 3.4176 & 0.4227 & 8.5751 & 2.9284 & 0.3415 & 6.5789 & 4.9246 & 0.7485 \\
\hline 05:00 & -14.8350 & -5.5997 & 9.2353 & 6.4985 & 2.7369 & 0.4212 & 6.8952 & 2.3402 & 0.3394 & 5.2932 & 3.9421 & 0.7448 \\
\hline 06:00 & -13.9283 & -7.7825 & 6.1458 & 4.3211 & 1.8247 & 0.4223 & 4.5838 & 1.5620 & 0.3408 & 3.5231 & 2.6228 & 0.7445 \\
\hline 07:00 & -16.8750 & -14.4800 & 2.3950 & 1.6800 & 0.7150 & 0.4256 & 1.7811 & 0.6139 & 0.3446 & 1.3768 & 1.0182 & 0.7396 \\
\hline 08:00 & -4.6538 & 14.0668 & 18.7207 & 13.1591 & 5.5616 & 0.4226 & 13.9530 & 4.7676 & 0.3417 & 10.6965 & 8.0242 & 0.7502 \\
\hline 09:00 & 19.9750 & 86.2767 & 66.3017 & 47.1156 & 19.1860 & 0.4072 & 50.0931 & 16.2086 & 0.3236 & 38.4008 & 27.9008 & 0.7266 \\
\hline $10: 00$ & 63.0883 & 251.6667 & 188.5783 & $\begin{array}{l}136.7707 \\
\end{array}$ & 51.8077 & 0.3788 & 146.2387 & 42.3396 & 0.2895 & 112.2701 & 76.3082 & 0.6797 \\
\hline 11:00 & 102.0417 & 376.2333 & 274.1917 & 202.0556 & 72.1361 & 0.3570 & 217.0180 & 57.1737 & 0.2635 & 166.8300 & 107.3617 & 0.6435 \\
\hline $12: 00$ & 85.6633 & 369.9667 & 284.3033 & 211.8194 & 72.4840 & 0.3422 & 228.3859 & 55.9175 & 0.2448 & 175.7461 & 108.5572 & 0.6177 \\
\hline 13:00 & 135.0333 & 460.2000 & 325.1667 & 246.0456 & 79.1210 & 0.3216 & 266.7699 & 58.3967 & 0.2189 & 205.5816 & 119.5851 & 0.5817 \\
\hline $14: 00$ & 149.5000 & 520.7167 & 371.2167 & 284.8296 & 86.3871 & 0.3033 & 310.5659 & 60.6508 & 0.1953 & 239.6626 & 131.5540 & 0.5489 \\
\hline 15:00 & 122.0467 & 346.7333 & 224.6867 & 173.2935 & 51.3932 & 0.2966 & 189.4235 & 35.2631 & 0.1862 & 146.2646 & 78.4221 & 0.5362 \\
\hline 16:00 & 57.7600 & 195.7333 & 137.9733 & 106.5282 & 31.4451 & 0.2952 & 116.6475 & 21.3258 & 0.1828 & 90.0947 & 47.8786 & 0.5314 \\
\hline 17:00 & 88.3833 & 265.0667 & 176.6833 & 137.6260 & 39.0573 & 0.2838 & 151.1354 & 25.5479 & 0.1690 & 116.8275 & 59.8559 & 0.5123 \\
\hline 18:00 & 45.0233 & 125.9167 & 80.8933 & 62.8995 & 17.9938 & 0.2861 & 69.0934 & 11.7999 & 0.1708 & 53.4121 & 27.4812 & 0.5145 \\
\hline 19:00 & -16.9908 & -13.3117 & 3.6792 & 2.8281 & 0.8511 & 0.3009 & 3.0996 & 0.5795 & 0.1870 & 2.4090 & 1.2702 & 0.5273 \\
\hline $20: 00$ & -34.4550 & -39.3500 & -4.8950 & -3.6746 & -1.2204 & 0.3321 & -3.9899 & -0.9051 & 0.2268 & -3.0580 & -1.8370 & 0.6007 \\
\hline 21:00 & -35.3600 & -39.1800 & -3.8200 & -2.8210 & -0.9990 & 0.3541 & -3.0454 & -0.7746 & 0.2543 & -2.3274 & -1.4926 & 0.6413 \\
\hline $22: 00$ & -34.1783 & -35.6850 & -1.5067 & -1.0975 & -0.4092 & 0.3728 & -1.1790 & -0.3276 & 0.2779 & -0.8913 & -0.6153 & 0.6904 \\
\hline 23:00 & -32.1117 & -34.7583 & -2.6467 & -1.9069 & -0.7398 & 0.3880 & -2.0406 & -0.6061 & 0.2970 & -1.5518 & -1.0948 & 0.7055 \\
\hline $00: 00$ & -31.4150 & -35.9217 & -4.5067 & -3.2133 & -1.2934 & 0.4025 & -3.4271 & -1.0796 & 0.3150 & -2.6137 & 930 & 0.7243 \\
\hline
\end{tabular}

\section{Results and Discussion}

The analysis of the data used in this work has been done using spreadsheet software that is available on most microcomputers. The daily data was recorded on a 10-minute interval basis and analysis was performed as is, to calculate the required temperature and vapor pressure gradient profiles, Bowen ratio values and finally the sensible and the latent heat fluxes, for the BR method, as explained in the previous section. These results were then averaged to obtain daily mean values for all the calculated parameters as well as for the net radiation, soil heat flux, and available energy. We then further categorized the daily 10-min data into hourly data by averaging which produced much more observable values for all the calculated parameters.

The PT and PM methods used the hourly data as input for the measured temperature to compute values for $L_{v}(T), \gamma(T), q_{\text {sat }}(T)$, and saturation vapour pressure $e_{\text {sat }}(T)$. These results are then used to determine the change of specific humidity with temperature, $s_{c c}(T)$, since both are a function of $s_{c c}$. We finally compute $L E$ and $H$ for both the Priestley-Taylor and the Penman-Monteith methods. Also computed are the Bowen ratios for the two methods, and the value of $F_{w}$ for the Penman-Monteith method. As in the BR method, we obtained daily means of the Sensible heat, Latent heat and Bowen ratio for both PT and PM methods.

Graphical methods were employed in the analysis to show variations of the parameters from the three methods, first on a diurnal basis and then on a daily basis for the Julian days in review. The graphs were compared to obtain probable relationships and to better interpret the partitioning of the available energy by the methods. 


\subsection{Diurnal Trends}

3.1.1 Temperature and vapor pressure

In this study, we observe that temperatures remained near normal to slightly above normal. The data collected from the 3-month period is characterized by a series of wet and dry spells. Some days include wet hours (e.g., Days 87 and 93) while others have just a few hours of rainfall. Dry days include days 83 and 86 . Very dry weather continued through days 97, 102 and 104 followed by much-above normal rainfall on days 106, 115 and 121.
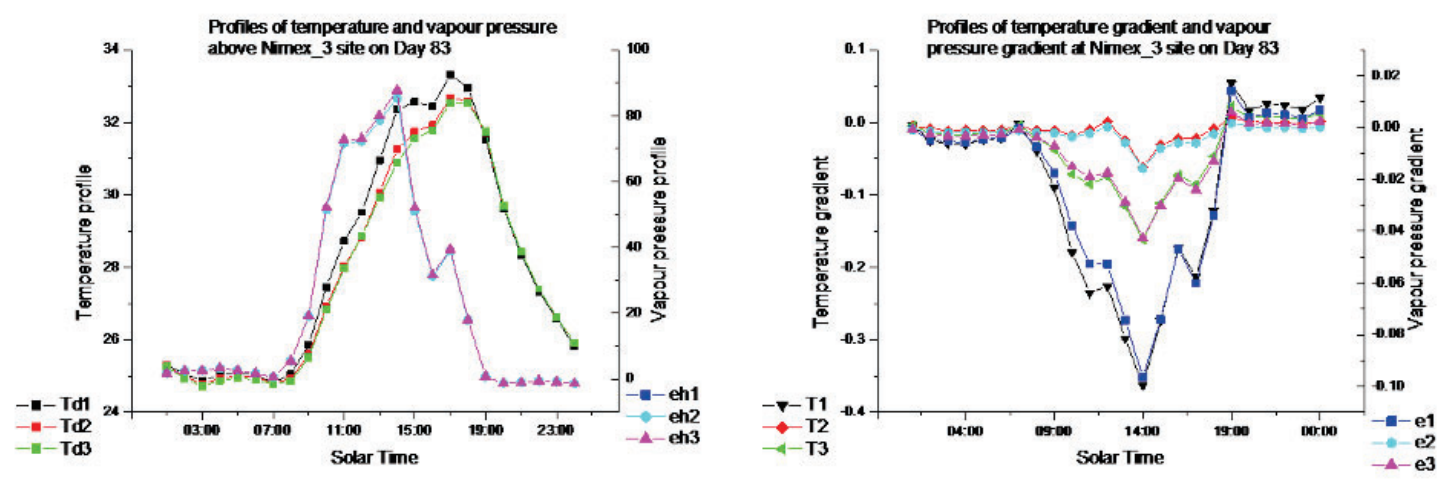

Figure 1(a) and (b). Profiles of temperature and vapor pressure as well as their gradients on Day 83

Vertical gradients in air temperature and moisture are measured using temperature and humidity sensors mounted at heights above the surface. Temperature and vapor pressure profiles for the three measurement heights were obtained for the Julian days investigated. The highest mean temperature of $27.88^{\circ} \mathrm{C}$ is recorded for height $6 \mathrm{~m}$ having a corresponding gradient of $-0.01{ }^{\circ} \mathrm{C} / \mathrm{m}$. In Fig. 1a, we observe that temperature and vapor pressure values are relatively constant in the early hours of the day until morning when they begin to rise sharply with temperature peak of $33.32^{\circ} \mathrm{C}$ (at 17:00 Hrs.) and vapor pressure of $87.78 \mathrm{~g} / \mathrm{kg}$ (at 14:00 Hrs.), decreasing afterwards. The profiles ranged from 24.82 to $33.32{ }^{\circ} \mathrm{C}$ for temperature and 3.13 to $5.12 \mathrm{~g} / \mathrm{kg}$ for vapor pressure. A similar agreement is observed for the gradients of temperature and vapor pressure (Fig. 1b), where the curves are inverted with respect to the profiles, reaching a minimum around midday and remaining constant at early mornings and late at night. Mean temperature gradient on day 83 was -0.09 and ranged between -0.36 to 0.05 while mean vapor gradient was estimated at -0.02 with a standard deviation of 0.03 and a range from -0.1 to 0.01 . 3.1.2 Components of the Surface Energy Budget

The differences between the BR, PT and PM systems were quantified for each component of the energy budget. The assumption is that the differences between the systems can be linked with inadequate partitioning and distribution of the fluxes, thus by examining differences between individual components of the energy budget produced by the observing systems, we may conclusively identify which components are in error.

Since $R_{n}$ and $G$ are measured on site by means of the sensors and are not system dependent, we consider particularly significant patterns in the mean diurnal cycles observed between the BR, PT and PM systems in both $\mathrm{H}$ and LE (Fig. 2). However, we still consider the partitioning of the available energy into the aerodynamic fluxes ( $\mathrm{H}$ and LE) by the three systems independently. This enabled the further observance of related patterns (Fig. 2). 

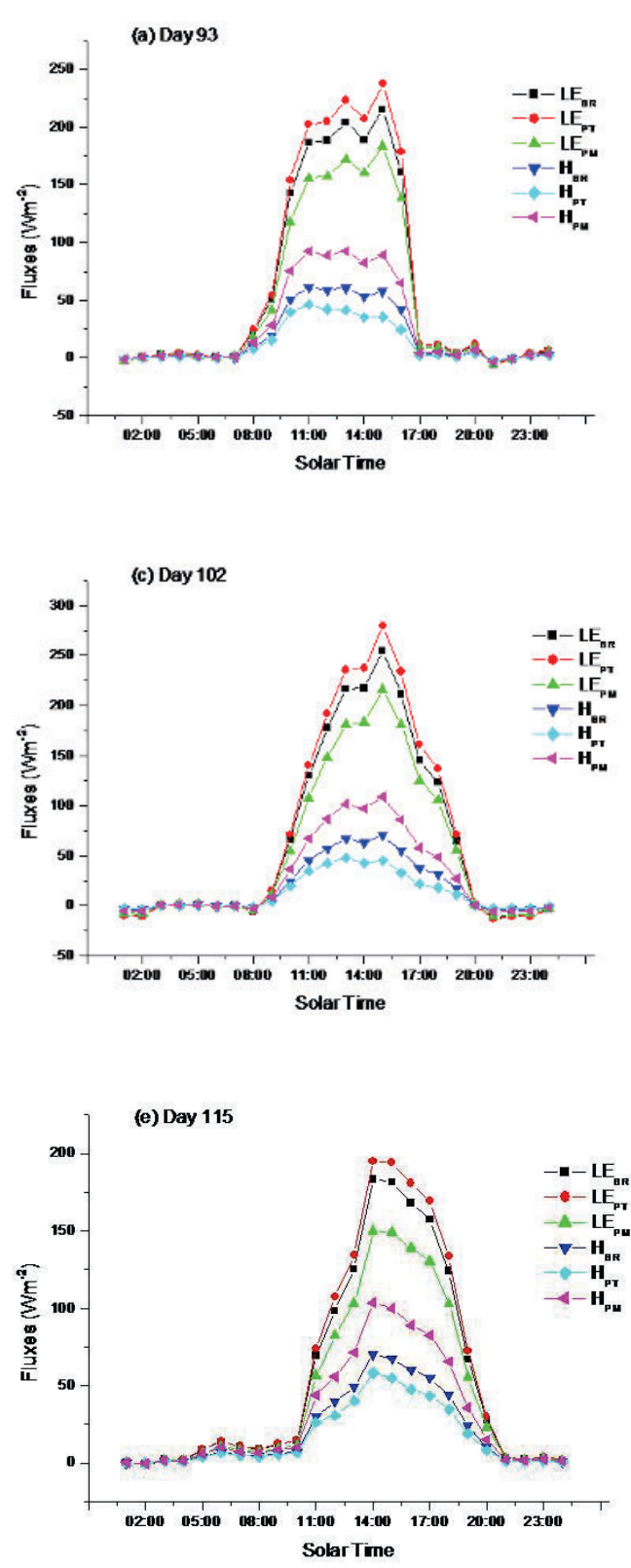
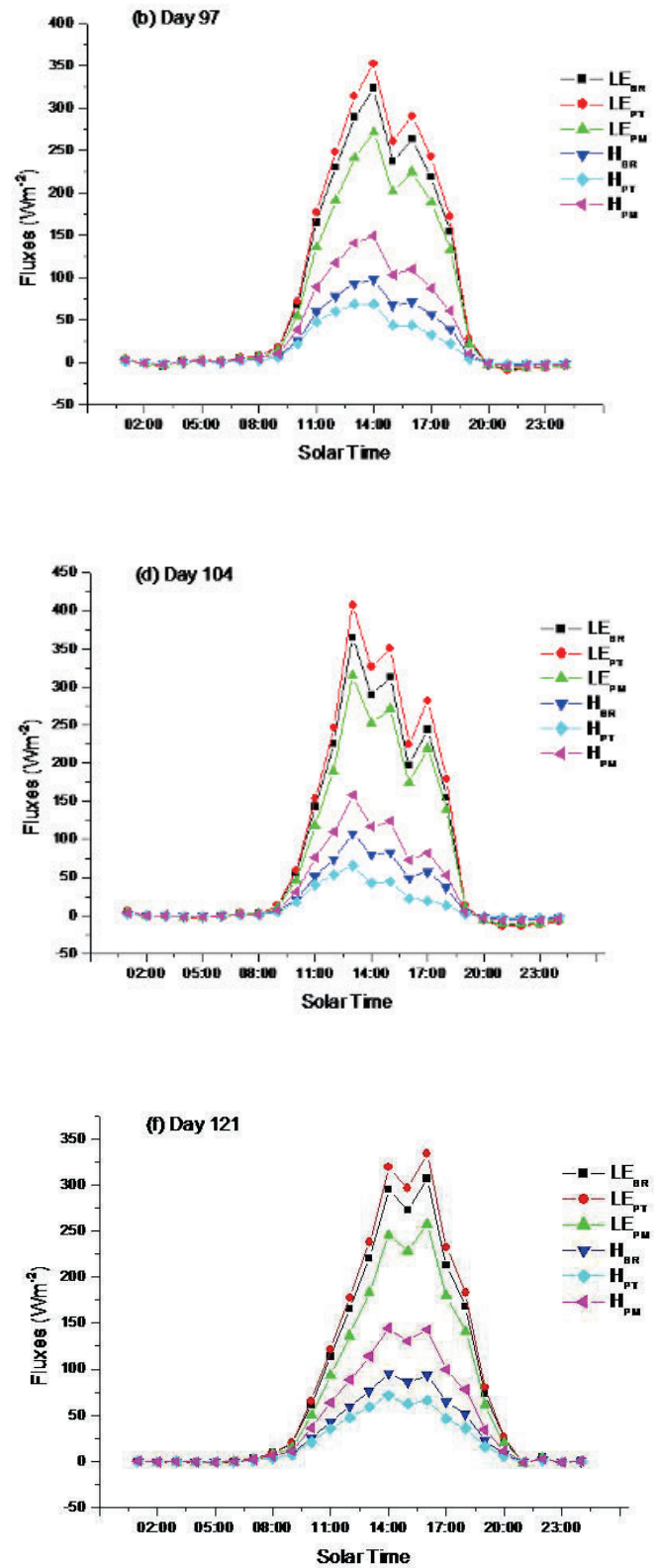

Figure 2(a)-(d). Diurnal cycle of sensible (H) and latent heat flux (LE) as estimated by the BR, PT and PM systems at Ibadan. The three systems used the net radiation and ground heat flux measured by the sensors at the site for six different days during the period under review. Here, we consider particularly significant patterns in the mean diurnal cycles observed between the BR, PT and PM systems in both H and LE.

Priestley-Taylor estimates for the LE were much larger than BR and PM estimates during all the days, although diurnal trends were similar, achieving slightly broad peaks during midday. The PM system underestimated the LE when compared to the other two methods. Diurnal trends in $\mathrm{H}$ were also similar, though significantly lower for all systems with respect to the LE. The PM estimates were significantly higher than those of the other two systems, with the greatest difference occurring on day 115 (a day characterized by much rainfall). Another point worthy of notice is that most of the fluxes cross the zero line at the same time, an indication that all of the fluxes are in phase. 

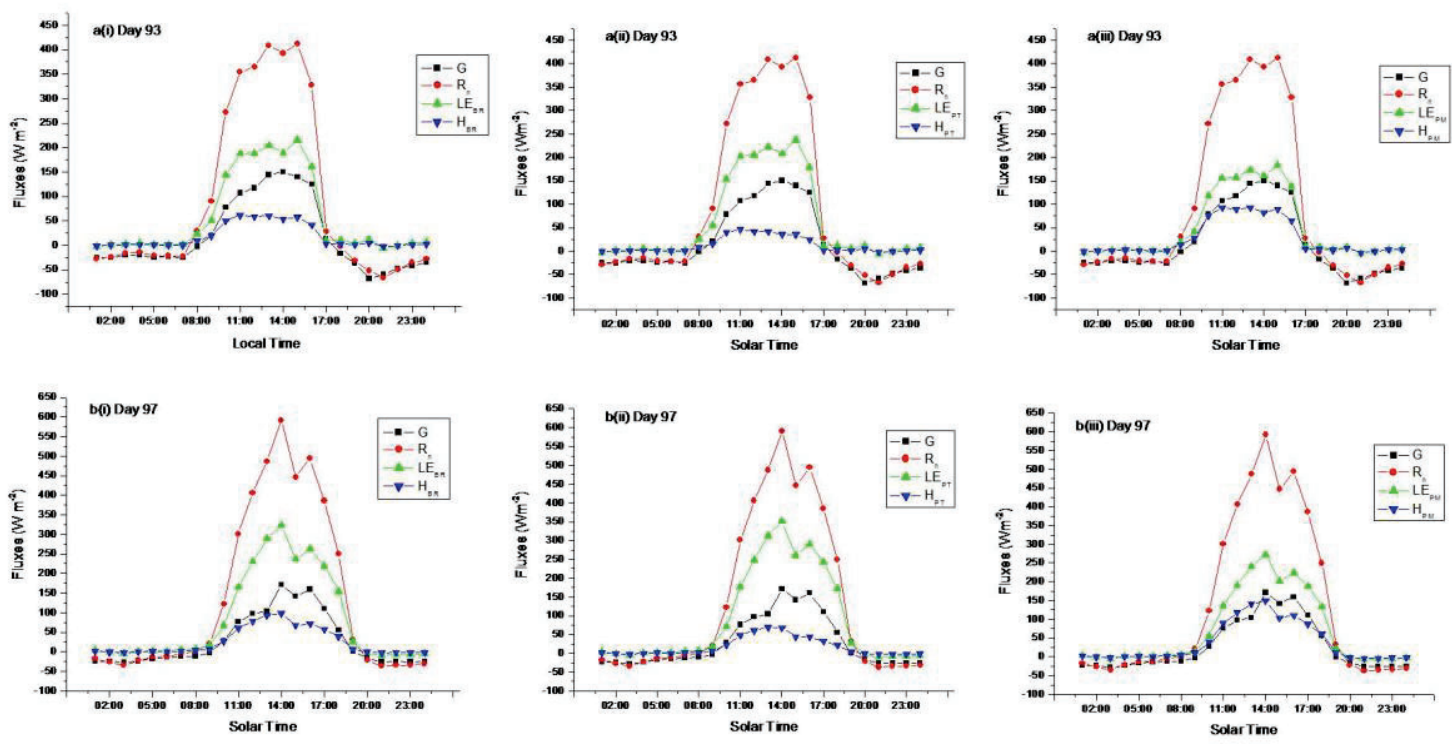

Figure 3. Daily mean cycle ground heat flux $(\mathrm{G})$, net radiation $\left(\mathrm{R}_{\mathrm{n}}\right)$, latent heat $(\mathrm{LE})$ and sensible heat flux $(H)$ as estimated by three methods - BR, PT and PM.

In Fig. 3, we consider the performance of the three methods in partitioning similar energy budget data separately and the relationships that can be inferred. In a (i-iii), it can be seen that the PT system performs best, perhaps closest to the BR system, in estimating the LE. The PT method overestimates LE by as much as $10.3 \%$ when compared to the BR method. However, this is reduced by its underestimate of $\mathrm{H}$ by about the same amount with respect to the BR method. The PM method underestimates LE by as much as $15.7 \%$ when compared to the BR method, performing poorly in the estimate of $\mathrm{H}$ with respect to BR. Thus, the PT method produces closer estimates of the aerodynamic fluxes $(\mathrm{H}+\mathrm{LE})$ better than the PM method with respect to the BR method. The difference in the PM and PT estimates of $\mathrm{H}$ and LE reaches up to $53.6 \mathrm{Wm}^{-2}$ in the afternoon when the sun is at its peak. This indicates a higher sensitivity to evaporation of the PT method than the PM method while at the same time suggests a lesser response to sensible heat with respect to the BR method. Similar patterns can be seen in b (i-iii), c (i-iii) and, d (i-iii) with the latter (Day 115) recording the lowest sensible heat, H for the PT method as a result of extended hours of rainfall.
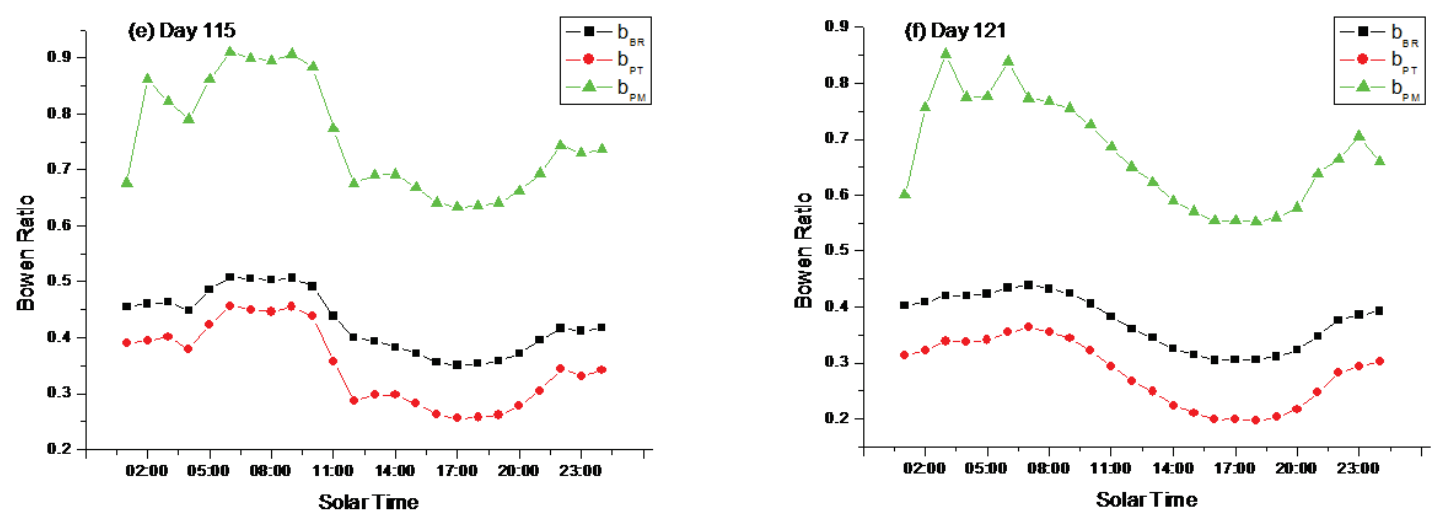

Figure 4. Daily mean diurnal cycle of Bowen ratio as estimated by the three methods; BR, PT and PM on days selected from the period.

Fig. 4 shows the daily mean diurnal cycle for the Bowen ratio estimated from the three methods. The Bowen ratio estimates from the PM method reach peaks twice; just before noon and at night-time. The PM method overestimates the Bowen ratio by $57.8 \%$ on day 104 and by over $80 \%$ on days 93,115 and 121 , with respect to the BR technique. The PT method, on the other hand, underestimates the Bowen ratio with respect to the BR technique. It performs closely similar to the BR technique recording peaks in the mornings and small 
broader peaks at night. The diurnal cycle is closely related to that of the BR method. A direct comparison of the PT and PM Bowen ratios indicates that the PM Bowen ratio was mostly/ generally higher during the period.

When comparing the mean diurnal Bowen ratios from the methods, a linear relationship is evident. The PT method provides the closest approximation to the BR method with a regression of 0.99 , a standard deviation of 0.0022 for $\mathrm{N}$ equals 24, whereas the PM method has Bowen ratio estimates that are often higher than the BR method as evident on day 102. Likewise on day 115, the PM technique produces higher estimates of Bowen ratio ranging between 0.63 and 0.91 whereas the PT method gives closer estimates ranging from 0.26 to 0.46 , with a diurnal mean of 0.35 , a regression of 0.99 and standard deviation of 0.0075 .

One other feature observed in the diurnal cycles of fluxes is the rapid increase in latent heat flux at sunrise. This sudden jump in flux noticeable particularly on days 93, 97, 102, 115 and 121 give rise to question on the observation; Is the rapid increase in LE flux real? If not, then is the PM method simply appropriating the available energy into its subsequent aerodynamic fluxes? A strong diurnal dependence of the partitioning is also evident in the surface fluxes. Minimal closure is observed during the early morning periods. However, closure reaches its maximum at mid-day before decreasing during the late afternoon. (Barr et al., 2006) detected a similar diurnal pattern in EC closure. The diurnal dependence of closure errors could be caused by dependence upon stability and fetch. Here, fetch is defined as the area upwind of a site that most influences the measurement of fluxes (Anderson et al., 2004; Gavilán and Berengena, 2007; Pearlmutter et al., 2005). The atmosphere is more stably stratified during the early morning and early evening periods. The size of the fetch area - as a function of wind speed, stability and measurement height - increases by an order of magnitude during stable conditions and includes a much greater area of heterogeneity.

\subsection{Daily Trends}

\subsubsection{Energy Budget Fluxes}

For additional analysis, the mean daily net (solar) radiation cycle for the period considered. The results show an average daily net radiation of approximately $100 \mathrm{Wm}^{-2}\left( \pm 50 \mathrm{Wm}^{-2}\right)$, with the highest value recorded on day 107 and the least on day 114, with a standard deviation of $20.87 \mathrm{Wm}^{-2}$. The ground heat flux, $\mathrm{G}$ shows lesser variation from a mean of $13.01 \mathrm{Wm}^{-2}$, a maximum value of $31.54 \mathrm{Wm}^{-2}$ on day 99 and an inconsistent low on day 87 , with a standard deviation of $11.43 \mathrm{Wm}^{-2}$. The available energy for partitioning into the aerodynamic fluxes, comprises a series of peaks, with a periodical mean of $99.72 \mathrm{Wm}^{-2}$ and ranging between $56.66 \mathrm{Wm}^{-2}$ and its highest value of $200.61 \mathrm{Wm}^{-2}$ on day 87. A similar cycle shows the mean daily aerodynamic flux partitioning for the period (Fig. 5). The estimates from the three methods show close similarities, with the PT method favoring partitioning into latent heat, LE while the PM method favored large partitioning into sensible heat, $\mathrm{H}$ with reference to the BR technique.
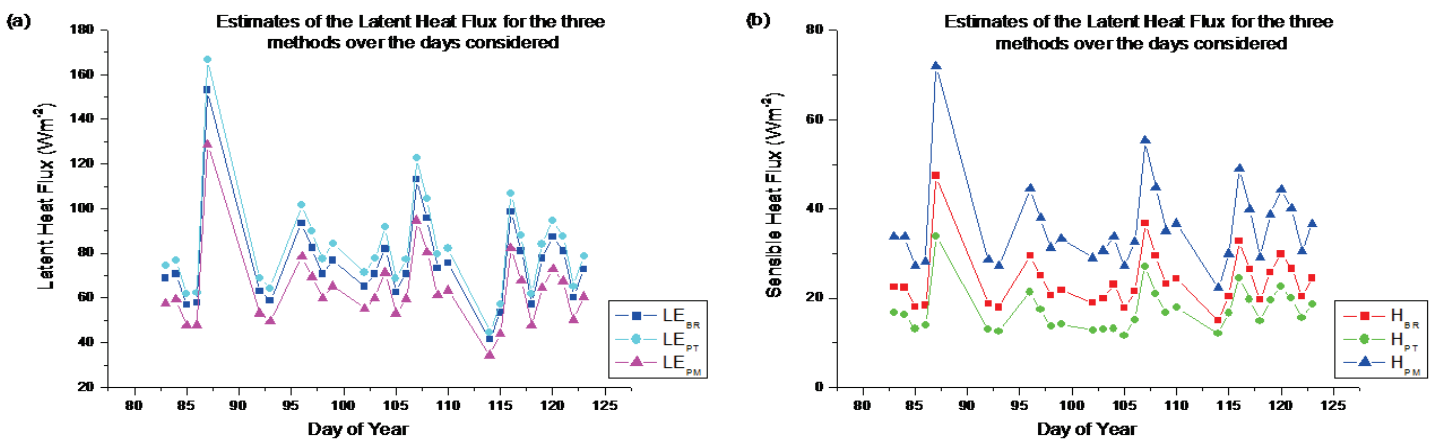

Figure 5. Daily estimates of (a) latent heat flux (LE), and (b) sensible heat flux (H) during an annual cycle using the three methods BR, PT and PM.

\section{Summary and Conclusion}

This project targeted the identification of problems associated with the partitioning of the surface energy budget by some selected methods. A number of sources for these problems were found. First, instrumentation error among net radiometers and soil moisture sensors, was found, which lead to greater uncertainty in $R_{n}$ and $G$. Secondly, heterogeneity of soil characteristics combined with instrument uncertainty in measuring soil temperature and below-ground soil heat flux, also contributed a great deal to the reduced measurement accuracy of $\mathrm{G}$. Such variability questions the spatial representativeness of point-scale measurements of $\mathrm{G}$.

Furthermore, analysis suggests that the measured latent heat flux is reasonable while the sensible heat flux may be significantly under-measured by the Priestley-Taylor technique. It can be inferred that the inability to effectively capture the fluxes plays a major role in the energy closure problem. However, it is still not clear why 
such a situation occurred at this flat and open site. Discussions could be channeled in both instrumentation and physical points of view. (Camuffo and Bernardi, 1982; Gouveia et al., n.d.; Massman, 1993) opined that the net radiation flux and the latent heat flux were the least erroneous while the soil heat flux and the sensible heat flux were the most error-prone for the same site. This position could result from the use of different evaluation methods but also from some uncertainties caused by incomplete observations.

The under-measurement of the sensible heat and the otherwise over-measurement of the latent heat are also associated with rainfall events. Low closure ratios usually occurred during rainy daytimes, while high closure ratios occurred during rain-free daytime. From the viewpoint of physical processes, horizontal advection may also play a different role in sensible and latent heat transport. At the NIMEX_3 site, the field measurements were not designed to address the problem of horizontal advection. However, the presence of horizontal advection may be inferred from testing the flux-variance similarity relationships for heat and water vapor. Results would reveal differences in the similarity constants for the two parameters, which then suggest that the sources and sinks of heat and water vapor for the bare soil surface may be different. Thus, the surface may be heterogeneous for the sinks and sources of heat while homogeneous for the sinks and sources of water vapor. Similar phenomena were reported in earlier studies (Heusinkveld et al., 2004; Malek, 1994). Therefore, the horizontal advection of latent heat may be negligible while that of sensible heat might be important.

We try to link the variations in Bowen ratio with the closure problem, observing that residuals of the energy budget appear to be inversely proportional to the daily Bowen ratio, that is, large positive residuals occur when the latent heat, LE is large. This result is consistent with those found by (Barr et al., 2006), who found decreasing closure with decreasing Bowen ratio. As differences between systems decreased, closure rates are expected to improve since the Bowen ratio also improved.

We have thus been able to appreciate the importance of instrument accuracy, site representativeness and theoretical assumptions to the measurement of surface fluxes. Also, we have seen that using data from a single site for model and satellite validation can pose serious implications. The following recommendations are therefore proposed for further study:

- The use of redundant instrumentation, when possible, to minimize sensor error and the effects of surface heterogeneity should be encouraged,

- Measurement of available energy, net radiation, and ground heat flux should be separated for the different systems in order to reduce the forcing of closure and aid in proper partitioning and characterization of the fluxes,

- It is suggested that collocated systems such as Eddy correlation, EC and BR systems be employed in identifying problems when estimating $\mathrm{H}$ and LE,

- Quantifying nearby biophysical parameters is essential and should include vegetation type and height, soil type and land use to properly understand the context in which measurements are made. A greater understanding of site properties aids in interpreting problems with non-closure and other data irregularities.

Although the three tested methods provide good agreement in the observations, as the energy budget closure is a sure test of reliability, we draw the following conclusions from the study:

1. The PM method has been recommended for future application in this region for its simplicity and consistent performance. Further optimization revealed that that a $\alpha$ constant value of 1.26 in the PT equation made the model perform well for this region, the PT estimation of $\mathrm{H}$ and $\mathrm{LE}$ are $17.27 \mathrm{Wm}^{-2}$ and $82.45 \mathrm{Wm}^{-2}$. This shows respective underestimations and overestimations of the surface fluxes. However, with day-time surface available energy, we observe the consistence of the PM method in providing a good mean estimation of the fluxes of $\mathrm{H}$ as $36.13 \mathrm{Wm}^{-2}$ and that of $\mathrm{LE}$ as $63.59 \mathrm{Wm}^{-2}$ with reference to the BR method. Hence, there is a strong reason to propose that the Penman-Monteith method should be preferred to the PriestleyTaylor method in partitioning and characterizing the surface energy balance for University of Ibadan.

2. Also, the mean Bowen ratio for the Penman-Monteith (0.66) is higher than that of the Priestley-Taylor $(0.28)$ during Julian days 83 - 123, therefore it should be adopted in the characterization of the budget data when the sensible heat flux appears underestimated or when the BR observations are to be rejected as a result of observational conditions such as wetness, unstable atmospheric conditions and others.

\section{References}

Adeniyi, M.O., Otunla, T., 2010. ESTIMATION OF SURFACE ENERGY FLUXES USING THE PENMAN MONTEITH METHOD IN A TROPICAL STATION. https://doi.org/10.13140/RG.2.2.12470.34889

Akinnubi, R.T., Adeniyi, M.O., 2019. The improvement of turbulent heat flux parameterization for use in the tropical regions using low wind speed excess resistance parameter. J. Adv. Model. Earth Syst. 11, 36363649.

Anderson, M.C., Norman, J.M., Mecikalski, J.R., Torn, R.D., Kustas, W.P., Basara, J.B., 2004. A multiscale remote sensing model for disaggregating regional fluxes to micrometeorological scales. J. Hydrometeorol. 5, 
$343-363$.

Barr, A.G., Morgenstern, K., Black, T.A., McCaughey, J.H., Nesic, Z., 2006. Surface energy balance closure by the eddy-covariance method above three boreal forest stands and implications for the measurement of the CO2 flux. Agric. For. Meteorol. 140, 322-337.

Beljaars, A.C.M., Holtslag, A. a. M., 1991. Flux Parameterization over Land Surfaces for Atmospheric Models. J. Appl. Meteorol. Climatol. 30, 327-341. https://doi.org/10.1175/15200450(1991)030<0327:FPOLSF>2.0.CO;2

Brotzge, J.A., Crawford, K.C., 2003. Examination of the surface energy budget: A comparison of eddy correlation and Bowen ratio measurement systems. J. Hydrometeorol. 4, 160-178.

Camuffo, D., Bernardi, A., 1982. An observational study of heat fluxes and their relationships with net radiation. Bound.-Layer Meteorol. 23, 359-368.

Castellví, F., Snyder, R.L., Baldocchi, D.D., 2008. Surface energy-balance closure over rangeland grass using the eddy covariance method and surface renewal analysis. Agric. For. Meteorol. 148, 1147-1160.

Collaizi, Paul D., Agam, Nurit, Tolk, Judy A, Evett, Steven R., H, 2014. Two-Source Energy Balance Model to Calculate E, T, and ET: Comparison of Priestley-Taylor and Penman-Monteith Formulations and Two Time Scaling Methods. Trans. ASABE 479-498. https://doi.org/10.13031/trans.57.10423

Field, R.T., Fritschen, L.J., Kanemasu, E.T., Smith, E.A., Stewart, J.B., Verma, S.B., Kustas, W.P., 1992. Calibration, comparison, and correction of net radiation instruments used during FIFE. J. Geophys. Res. Atmospheres 97, 18681-18695.

Foken, T., Aubinet, M., Finnigan, J.J., Leclerc, M.Y., Mauder, M., Paw U, K.T., 2011. Results of a panel discussion about the energy balance closure correction for trace gases. Bull. Am. Meteorol. Soc. 92, ES13ES18.

Fritschen, L.J., Simpson, J.R., 1989a. Surface energy and radiation balance systems: General description and improvements. J. Appl. Meteorol. Climatol. 28, 680-689.

Fritschen, L.J., Simpson, J.R., 1989b. Surface energy and radiation balance systems: General description and improvements. J. Appl. Meteorol. Climatol. 28, 680-689.

Gavilán, P., Berengena, J., 2007. Accuracy of the Bowen ratio-energy balance method for measuring latent heat flux in a semiarid advective environment. Irrig. Sci. 25, 127-140.

Gouveia, F.J., Leach, M.J., Shinn, J.H., n.d. MEASUREMENTS OF NET RADIATION, GROUND HEAT FLUX AND SURFACE TEMPERATURE IN AN URBAN CANYON 4.

Ha, K.-J., Mahrt, L., 2003. Radiative and turbulent fluxes in the nocturnal boundary layer. Tellus Dyn. Meteorol. Oceanogr. 55, 317-327.

Heusinkveld, B.G., Jacobs, A.F.G., Holtslag, A.A.M., Berkowicz, S.M., 2004. Surface energy balance closure in an arid region: role of soil heat flux. Agric. For. Meteorol. 122, 21-37.

Kilinc, M., Beringer, J., Hutley, L.B., Haverd, V., Tapper, N., 2012. An analysis of the surface energy budget above the world's tallest angiosperm forest. Agric. For. Meteorol. 166, $23-31$.

Leuning, R., Van Gorsel, E., Massman, W.J., Isaac, P.R., 2012. Reflections on the surface energy imbalance problem. Agric. For. Meteorol. 156, 65-74.

Liu, H., Foken, T., 2001. A modified Bowen ratio method to determine sensible and latent heat fluxes. Meteorol. Z. 10, 71-80. https://doi.org/10.1127/0941-2948/2001/0010-0071

Malek, E., 1994. Calibration of the Penman wind function using the Bowen ratio energy balance method. J. Hydrol. 163, 289-298.

Massman, W.J., 1993. Errors associated with the combination method for estimating soil heat flux. Soil Sci. Soc. Am. J. 57, 1198-1202.

Mauder, M., Foken, T., Cuxart, J., 2020. Surface-energy-balance closure over land: a review. Bound.-Layer Meteorol. 177, 395-426.

Pearlmutter, D., Berliner, P., Shaviv, E., 2005. Evaluation of Urban Surface Energy Fluxes Using an Open-Air Scale Model. J. Appl. Meteorol. 44, 532-545. https://doi.org/10.1175/JAM2220.1

Stannard, D.I., 1993. Comparison of Penman-Monteith, Shuttleworth-Wallace, and modified Priestley-Taylor evapotranspiration models for wildland vegetation in semiarid rangeland. Water Resour. Res. 29, 13791392.

Suleiman, A.A., Hoogenboom, G., 2007. Comparison of Priestley-Taylor and FAO-56 Penman-Monteith for daily reference evapotranspiration estimation in Georgia. J. Irrig. Drain. Eng. 133, 175-182.

Twine, T.E., Kustas, W.P., Norman, J.M., Cook, D.R., Houser, P.R., Meyers, T.P., Prueger, J.H., Starks, P.J., Wesely, M.L., 2000. Correcting eddy-covariance flux underestimates over a grassland. Agric. For. Meteorol. 103, 279-300. https://doi.org/10.1016/S0168-1923(00)00123-4

Yang, K., Koike, T., Ishikawa, H., Ma, Y., 2004. Analysis of the Surface Energy Budget at a Site of GAME/Tibet using a Single-Source Model. J. Meteorol. Soc. Jpn. 82, 131-153. https://doi.org/10.2151/jmsj.82.131 